\title{
Development of highly faceted reduced graphene oxide-coated copper oxide and copper nanoparticles on a copper foil surface
}

\author{
Rebeca Ortega-Amaya*1, Yasuhiro Matsumoto ${ }^{1,2}$, Andrés M. Espinoza-Rivas ${ }^{1}$, \\ Manuel A. Pérez-Guzmán² and Mauricio Ortega-López ${ }^{1,2}$
}

\section{Full Research Paper}

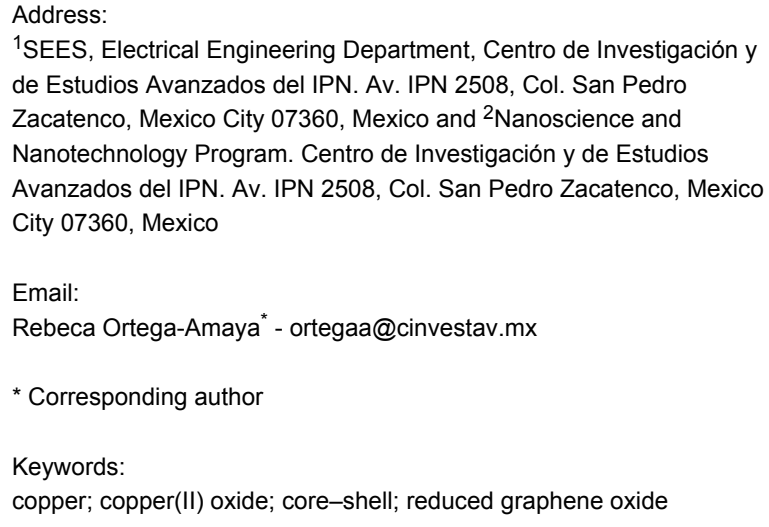

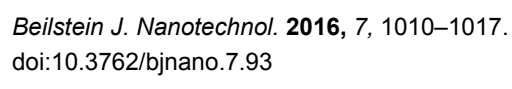

\begin{abstract}
This work describes the formation of reduced graphene oxide-coated copper oxide and copper nanoparticles $\left(\mathrm{rGO}^{-\mathrm{Cu}} \mathrm{O}_{2} \mathrm{ONP}\right.$, $\mathrm{rGO}-$ CuNPs) on the surface of a copper foil supporting graphene oxide (GO) at annealing temperatures of $200-1000{ }^{\circ} \mathrm{C}$, under an Ar atmosphere. These hybrid nanostructures were developed from bare copper oxide nanoparticles which grew at an annealing temperature of $80^{\circ} \mathrm{C}$ under nitrogen flux. The predominant phase as well as the particle size and shape strongly depend on the process temperature. Characterization with transmission electron microscopy and scanning electron microscopy indicates that $\mathrm{Cu}^{\circ} \mathrm{Cu}_{2} \mathrm{O}$ nanoparticles take $\mathrm{rGO}$ sheets from the $\mathrm{rGO}$ network to form core-shell $\mathrm{Cu}-\mathrm{rGO}$ or $\mathrm{Cu}_{2} \mathrm{O}-\mathrm{rGO}$ nanostructures. It is noted that such ones increase in size from 5 to $800 \mathrm{~nm}$ as the annealing temperature increases in the $200-1000{ }^{\circ} \mathrm{C}$ range. At $1000{ }^{\circ} \mathrm{C}, \mathrm{Cu}$ nanoparticles develop a highly faceted morphology, displaying arm-like carbon nanorods that originate from different facets of the copper crystal structure.
\end{abstract}

\section{Introduction}

In the last years, graphene oxide $(\mathrm{GO})$ and reduced graphene oxide (rGO) have emerged as suitable candidates to prepare graphene-based nanocomposites [1,2], including those based on
GO/inorganic nanoparticles [3]. The opportunity to combine GO with inorganic nanoparticles has led to nanocomposites with multiple functionalities $[4,5]$. Because of this, nanocom- 
posites based on GO/inorganic nanoparticles are currently of interest for applications in biomedicine, energy production, electronics and environmental remediation [6-8].

A special class of composites based on GO/inorganic nanoparticles is the one in which the inorganic nanoparticle is protected against degradation by coating with a suitable material (shell) $[9,10]$. Actually, silica, polymers and graphitic materials hold promise to produce highly stable well-protected metal or metal oxide nanoparticles [11]. In particular, $\mathrm{rGO}-\mathrm{Cu}$ core-shell nanostructures have been synthesized by CVD $[12,13]$, hydrothermal synthesis [14] and pyrolysis of an organocopper compound [15-17].

In a previous work, the authors reported the effective reduction of chemically exfoliated GO using a copper foil as the GO support. It was found that the final product consisted of rGO sheets decorated with $\mathrm{Cu}$ or $\mathrm{Cu}_{2} \mathrm{O}$ nanoparticles. To explain the presence of unoxidized $\mathrm{Cu}$ nanoparticles it was suggested that rGO sheets might coat $\mathrm{Cu}$ to prevent oxidation [18].

The present work reports further studies on the abovementioned $\mathrm{Cu}$-based nanoparticles. Interestingly, they develop a highly faceted morphology and are actually coated with rGO sheets. The rGO-coated Cu-based nanoparticles developed at temperatures in the range of $200-1000{ }^{\circ} \mathrm{C}$ starting from bare $\mathrm{Cu}_{2} \mathrm{O}$ nanocrystals that formed at $80^{\circ} \mathrm{C}$. Their morphology and the inorganic predominant phase strongly depended on the annealing temperature.

\section{Experimental}

\section{Materials}

Graphite flakes (+100 mesh), sodium nitrate ( $\geq 99 \%)$, potassium permanganate $(\geq 99 \%)$ and hexane $(\geq 99 \%)$ were purchased from Sigma-Aldrich. Sulfuric acid (95-98\%) was obtained from Reproquifin. Hydrogen peroxide (30\%), acetone $(99.77 \%)$ and copper foil $(99.99 \%)$ were obtained from J.T. Baker. Ethanol (99.5\%) was purchased from Reasol. All reagents were used as received without further purification.

\section{Preparation of the rGO sheets and copper- based nanoparticles composite}

As described in our earlier work [18], GO was prepared from natural graphite flakes by a modified Hummers method $[19,20]$. GO was dispersed in water $(2 \mathrm{mg} / \mathrm{mL})$ and then drop cast on a previously cleaned $\mathrm{Cu}$ foil $\left(0.02 \mathrm{~mm}\right.$ thick and $\left.1 \times 1 \mathrm{~cm}^{2}\right)$ to form a thin film. Before the high temperature process, the sample was dried at $80^{\circ} \mathrm{C}$ under nitrogen flux for $15 \mathrm{~min}$.

The thermal process leading to the reduction of GO and the formation of $\mathrm{Cu}$-based nanoparticles was carried out in an atmospheric pressure CVD apparatus equipped with a quartz tube. The annealing process was performed at 200, 400, 600, 800 and $1000{ }^{\circ} \mathrm{C}$ under an inert $\mathrm{Ar}$ atmosphere for $1 \mathrm{~h}$. For characterization, the rGO films were peeled off with stainless steel tweezers.

\section{Characterization}

The structure and morphology were studied using transmission electron microscopy (TEM, JEOL 2010 and HR-TEM, JEOL ARM 200F), field emission scanning electron microscopy (FESEM, Zeiss Auriga). Energy dispersive X-ray spectrometry (EDS, Bruker Xflash 5010 detector) was used to characterize composition.

\section{Results and Discussion Formation of initial nanoparticles}

We prepared a series of samples of GO supported on a $\mathrm{Cu}$ foil, as described in the Experimental section. FE-SEM images in Figure 1 show the surface morphology of the substrate copper foil (a) before and (b) after GO was deposited and dried at $80{ }^{\circ} \mathrm{C}$. The bare $\mathrm{Cu}$ foil surface exhibits particles $7-8 \mathrm{~nm}$ in size and structural defects. The surface chemical composition deter-
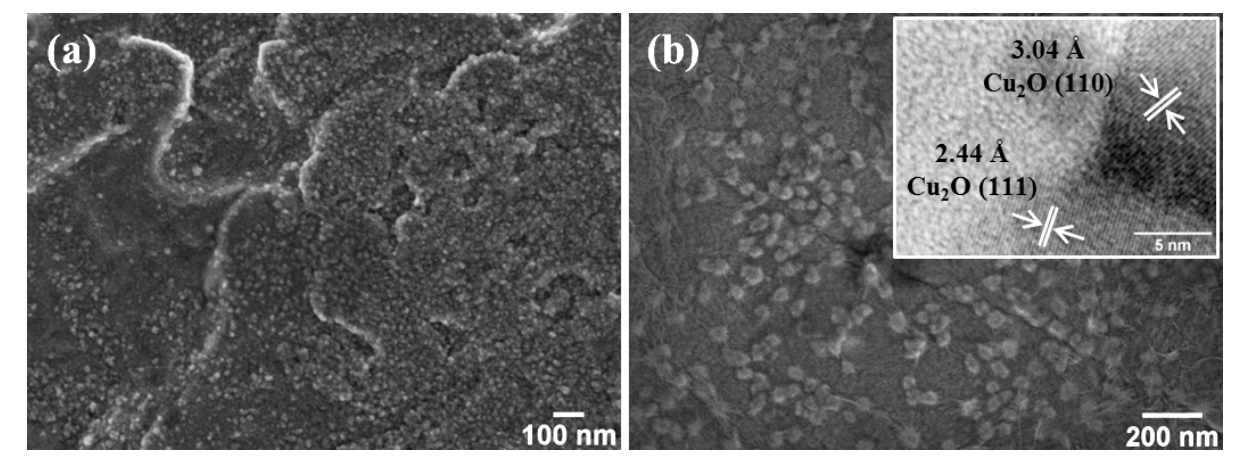

Figure 1: FE-SEM images of the copper foil (a) before and (b) after GO was deposited and dried at $80^{\circ} \mathrm{C}$. The inset of (b) shows the TEM image with an inter-planar spacing of 3.04 and $2.44 \AA$, corresponding to the (110) and (111) planes of cubic $\mathrm{Cu}_{2} \mathrm{O}$, respectively. 
mined by EDS revealed the existence of oxygen probably forming a native copper oxide layer $\left(\mathrm{Cu}_{x} \mathrm{O}\right)$ and carbonaceous species as adsorbed impurities. The inset of Figure $1 \mathrm{~b}$ shows a TEM image of nanoparticles grown at $80^{\circ} \mathrm{C}$.

After being detached and analyzed by TEM, it was seen that well-crystallized $\mathrm{Cu}_{2} \mathrm{O}$ nanoparticles developed during the annealing at $80^{\circ} \mathrm{C}$ (inset in Figure 1b). In our previous work we assumed that they developed following a mechanism similar to that proposed by Glover and co-workers [21]. They demonstrated that $\mathrm{Cu}$ nanoparticles ( $\mathrm{CuNPs}$ ) can be formed on the surface of copper objects exposed to ambient humidity for a few minutes. We believe that during the drying process similar conditions to those proposed by Glover et al. could be established which lead to the formation of CuNPs, which oxidized further due to interaction with water vapor.

\section{Development and phase evolution of Cu-based nanoparticles}

After being annealed at temperatures of $200-1000{ }^{\circ} \mathrm{C}$ under inert atmosphere, both the morphology and phase composition of initial $\mathrm{Cu}_{2} \mathrm{O}$ nanoparticles dramatically changed. In the entire annealing temperature range, faceted $\mathrm{rGO}$-coated copper oxide or copper nanoparticles ( $\mathrm{rGO}-\mathrm{Cu}_{2} \mathrm{ONPs}$, rGO-CuNPs) were obtained; the predominant phase of inorganic core being determined by annealing temperature.
Figure 2 displays TEM images of samples prepared at 200-600 ${ }^{\circ} \mathrm{C}$ for $1 \mathrm{~h}$. In this temperature range, the initial $\mathrm{Cu}_{2} \mathrm{O}$ phase preserves in the inorganic core of rGO-coated NPs. Figure $2 \mathrm{~b}$ and insets in Figure 2c,d provide details about the interplanar distance of the carbon shell as well as the inorganic core, corroborating that they correspond to $\mathrm{rGO}$ and $\mathrm{Cu}_{2} \mathrm{O}$, respectively.

It is noteworthy that $\mathrm{Cu}_{2} \mathrm{ONPs}$ were not observed when experiments were done using GO-free $\mathrm{Cu}$ foil substrates. Therefore, it is quite probably that the Cu-based NPs obtained at 200-1000 ${ }^{\circ} \mathrm{C}$ develop from the preformed copper oxide nanoparticles, which grew during the GO-copper foil sample preparation.

It was reported that the melting process of bulk materials involves a pre-melting stage in which the surface melts at temperatures lower than the bulk material melting point [22,23]. In fact, kinetics studies on metal melting revealed that the premelting temperature depends partly on the surface microstructure and partly on surface-adsorbed impurities [24]. It has also been reported that, for nanostructured materials, the melting point strongly depends on the size and it is lower than that of the bulk counterpart [25]. For instance, bulk $\mathrm{Cu}$ melts around $1084^{\circ} \mathrm{C}$ [26], whereas $40 \mathrm{~nm}$ size CuNPs were found to melt at $190{ }^{\circ} \mathrm{C}$, and the surface melting begins around $180^{\circ} \mathrm{C}$ [27].
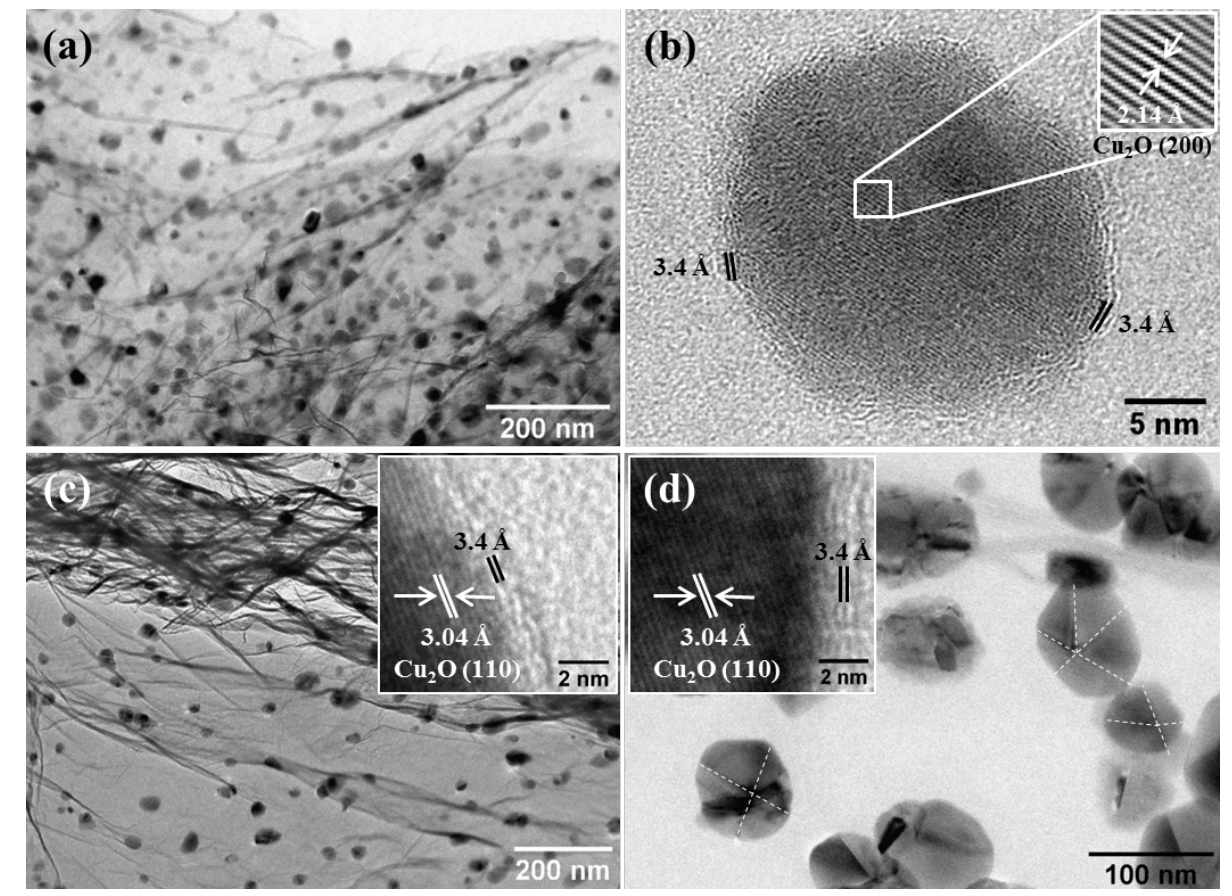

Figure 2: TEM images of samples annealed at (a,b) $200{ }^{\circ} \mathrm{C}$, (c) $400{ }^{\circ} \mathrm{C}$, (d) $600{ }^{\circ} \mathrm{C}$ for $1 \mathrm{~h}$. The insets of (b-d) provide details of the interplanar spacing of both, the $\mathrm{Cu}_{2} \mathrm{O}$ core and the $\mathrm{rGO}$ shell. The dotted lines on the nanoparticles image of (d) were added to visualize the faceted morphology of the $\mathrm{Cu}_{2} \mathrm{ONPs}$. 
As shown in Figure 1a, the copper foil surface displays a finegrained morphology probably comprising native $\mathrm{Cu}_{x} \mathrm{O}$ grains and structural defects that could promote the melting on the $\mathrm{Cu}$ foil surface even at $200^{\circ} \mathrm{C}$. On this basis, we assumed that upon raising the temperature, the initial $\mathrm{Cu}_{2} \mathrm{ONPs}$ partially melt, then they interact with the GO network to be finally wrapped in GO sheets. The $\mathrm{rGO}-\mathrm{Cu}_{2} \mathrm{ONPs}$ diffuse on the partially melted sur- face to agglomerate and coalesce and so to form bigger nanostructures. During coalescence, rGO catalytically decomposes producing carbon oxygenated species (epoxide, $\mathrm{COOH}, \mathrm{C}-\mathrm{OH}$, $\mathrm{CO}_{2}$ and $\mathrm{CO}$ ) and water vapor [28]. Once the nanoparticles attain a certain size, the rGO sheets rearrange at the nanoparticle surface to produce a hermetic rGO coating for $\mathrm{Cu}_{2} \mathrm{O}$ or CuNPs (Figure 3).

\section{GO sheets \\ rGO-wrapped Cu based NPs \\ rGO sheets \\ - carbon oxygenated species}

(a)
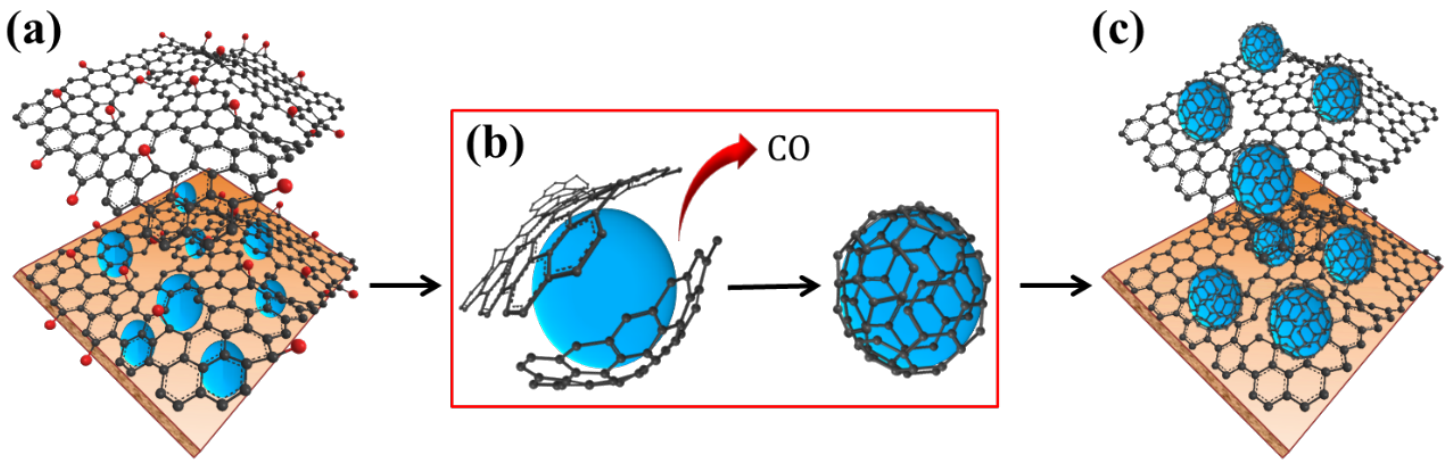

(g)
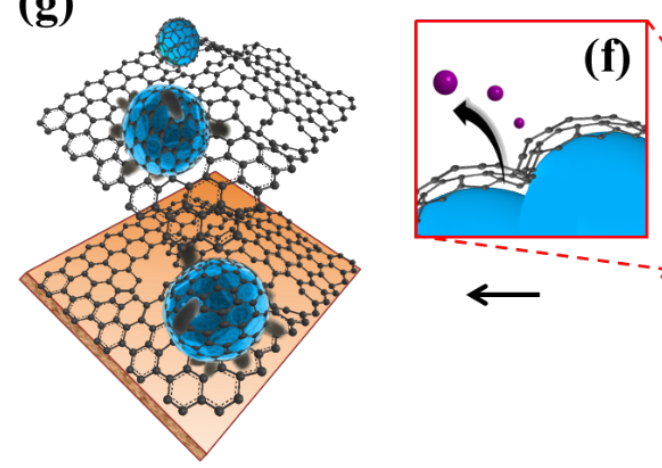

(e)
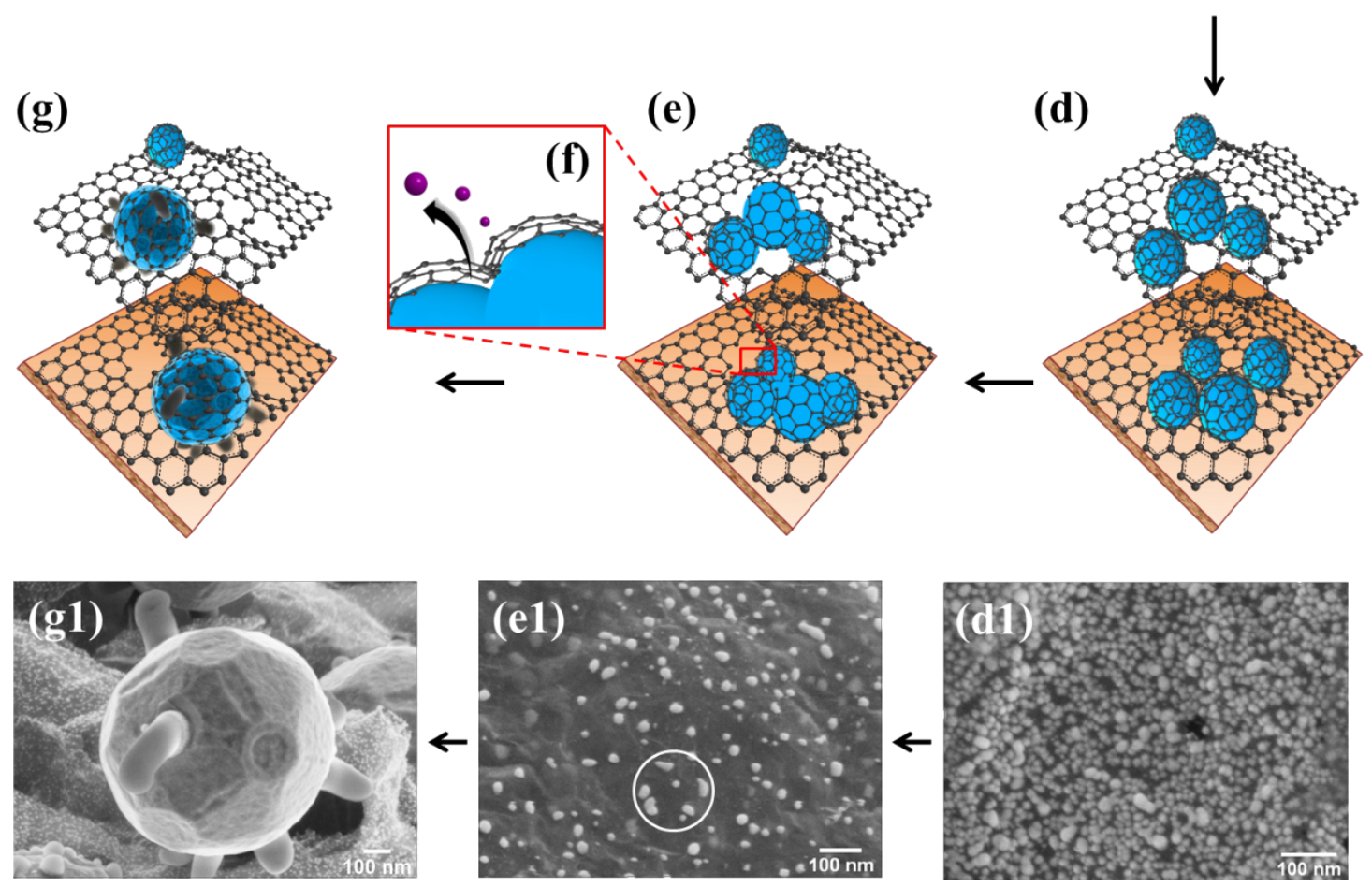

Figure 3: Scheme of the proposed mechanism for the formation of rGO-Cu $\mathrm{ONPs}_{2}$ and rGO-CuNPs: (a) The $\mathrm{Cu}_{2} \mathrm{ONPs}$ developed during the annealing at $80^{\circ} \mathrm{C}$. Upon raising the temperature from 200 to $1000^{\circ} \mathrm{C}$ : (b) reduction of GO sheets (with CO and water vapor emission), and GO wrapping of $\mathrm{Cu}_{2} \mathrm{O}\left(200-600^{\circ} \mathrm{C}\right)$ or $\mathrm{Cu}\left(800-1000^{\circ} \mathrm{C}\right) \mathrm{NPs}$, (c) surface diffusion, (d) agglomeration and (e) coalescence of adjacent NPs. (f) At the partially melted Cu surface, rGO sheets self-assemble to develop the rGO coating. (g) Equilibrium crystal shape of representative rGO-CuNPs at $1000{ }^{\circ} \mathrm{C}$. FE-SEM images picturing the steps described above: (d1) agglomeration, (e1), coalescence (circle) and (g1) equilibrium crystal shape. Note that, at annealing temperatures of $800-1000{ }^{\circ} \mathrm{C}$, copper oxide transforms into copper via reduction by $\mathrm{CO}\left(\mathrm{Cu}_{2} \mathrm{O}+\mathrm{CO} \rightarrow 2 \mathrm{Cu}+\mathrm{CO}_{2}\right)$. 
It is thought that, at $800-1000{ }^{\circ} \mathrm{C}$, carbonaceous species produced during coalescence could establish carbon supersaturation conditions at the partially melted particle surface, and then to promote the formation of a well-closed conformal coating at the CuNP surface. This might explain the stability against oxidation observed in these particles.

In regarding to dominant phase, we propose that $\mathrm{Cu}_{2} \mathrm{O}$ reacts with gaseous carbonaceous species derived from the GO reduction process to become $\mathrm{Cu}$, this depending on the amount of $\mathrm{CO}$ evolved during such a thermal process.

The carbothermal reduction of copper oxide has been studied by several authors, and the involved chemistry and pathway toward the copper oxide reduction appear to be very complex processes [29-31]. Experiments on the reduction of $\mathrm{CuO}$ by $\mathrm{CO}$ carried out by X. Wang et al. [29] revealed that $\mathrm{CuO}$ decomposes either directly to metallic copper when high amounts of $\mathrm{CO}$ were supplied or via formation of $\mathrm{Cu}_{2} \mathrm{O}$ when $\mathrm{CO}$ supply was limited.

Because the detachment of the oxidative species from the GO plane is a temperature-activated process, we suggest that, in the interval from 200 to $600{ }^{\circ} \mathrm{C}$, CO does not evolve in sufficient amounts to completely reduce the existent copper oxide phase. The resultant nanoparticles increase in size preserving the original phase. In the same view, in the high-temperature range $\left(800-1000{ }^{\circ} \mathrm{C}\right)$, copper oxide was totally converted to copper via reduction by $\mathrm{CO}$.

After being rGO-coated, the NPs attain their equilibrium size and shape depending on the undercooling temperature. Figure 4
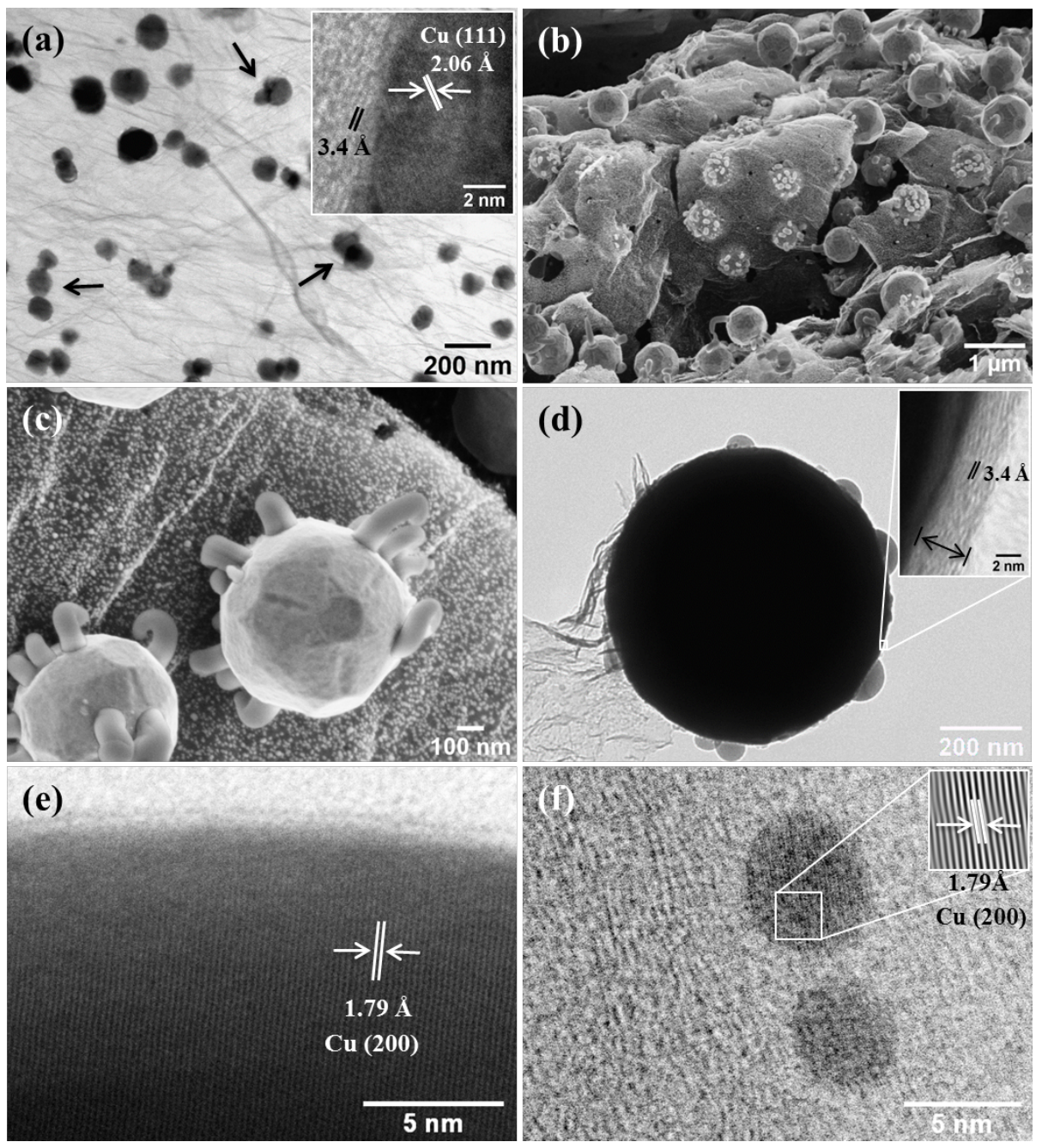

Figure 4: (a) TEM image of a sample annealed at $800^{\circ} \mathrm{C}$ for $1 \mathrm{~h}$. (b,c) Low- and high-magnification FE-SEM. (d) TEM images of sample prepared at $1000{ }^{\circ} \mathrm{C}$ for $1 \mathrm{~h}$. Inset in (d) provides details of rGO sheets coating the Cu core. (e) The Cu core HR-TEM image and (f) small Cu nanoparticles in the background (see text). Note that, due to the relative large size of $\mathrm{Cu}$ nanostructures for TEM observation (Figure $3 \mathrm{~d}$ and inset), the Cu nanostructure itself and its core-shell feature were separately analyzed. 
displays TEM and HR-TEM images of samples prepared at $800-1000{ }^{\circ} \mathrm{C}$. In this temperature range, elemental $\mathrm{Cu}$ develops as the predominant inorganic phase in the core of the rGOcoated nanoparticles. Notice that the $\mathrm{Cu}_{2} \mathrm{O}$ and CuNPs developed a faceted shape, i.e., their equilibrium crystal shape which is determined by the surface energy [32].

\section{Equilibrium crystal shape development}

In all cases, TEM or FE-SEM images revealed that polydisperse $\mathrm{rGO}-\mathrm{Cu}$ and $\mathrm{rGO}-\mathrm{Cu}_{2} \mathrm{ONPs}$ were obtained, some of them displayed a highly faceted morphology. Temperatures lower than $1000{ }^{\circ} \mathrm{C}$ resulted in particles $5-170 \mathrm{~nm}$ in size with irregular shapes. The considerable dispersion in size and shape can be attributed to nanoparticle coalescence, as indicated by the arrows in Figure 4a.

The FE-SEM images (Figure 4b,c) display the striking morphology of the sample prepared at $1000{ }^{\circ} \mathrm{C}$. It consists of highly faceted core-shell $\mathrm{Cu}$-rGO nanostructures and small, nearly monodisperse $3 \mathrm{~nm}$ in size, rGO-CuNPs, all of them decorating the $\mathrm{rGO}$ sheets. Some holes in the rGO network are also observed. Previously, we suggested such holes originate from the carbon consumption by the CuNP to get the carbon coating. It is also seen that faceted nanostructures have curved rod-shaped nanostructures attached to specific crystal planes.

As indicated in Figure 4c, d, Cu nanoparticles developed a different faceted Wulff-like structure (or equilibrium crystal shapes [32]). It has been reported that the equilibrium crystal shape for a given material depends partly on the crystalline structure of its bulk counterpart, and partly on the experimental parameters, such as processing temperature, time, and impurity control [33-35]. For bulk $\mathrm{Cu}$, that crystallizes in the fcc structure, its possible equilibrium crystal shapes exhibit the $\{111\}$, $\{100\},\{110\}$ and $\{113\}$ facets, because the Wulff shapes are determined by the lowest energy crystalline planes, as reported by Chatain and co-workers [36].
We carried out high angle annular dark field (HAADF) measurements to assess the chemical composition of the faceted nanoparticles. HAADF images and EDS line scans of a $\mathrm{Cu}-\mathrm{rGO}$ nanoparticle and a rod-shaped nanostructure are shown in Figure 5a,b, respectively. From the EDS line-scan analysis in Figure $5 \mathrm{a}$ it is seen that the chemical composition of the particle mostly comprises copper and carbon, so corroborating the core-shell structure for faceted Cu-rGO nanoparticle. It is seen that oxygen is also present at low levels because of the partial removal of oxygenated groups from the graphene sheet. An EDS line-scan analysis across a rod-shaped nanostructure (Figure 5b) revealed that it mostly comprised of carbon and traces of copper. We have assumed that the curved rod-shaped nanostructures grow by the catalytic decomposition of GO sheets into carbon and oxygenated species, so promoting carbon supersaturation on the facet surface, and then nucleation and growth.

The FE-SEM image (Figure 6) shows the faceted morphology of the core-shell $\mathrm{Cu}$-rGO particle of the sample prepared at $1000{ }^{\circ} \mathrm{C}$, and the corresponding three-dimensional equilibrium crystal shape created using the Wulffman freeware [37,38] (Figure 6b). For the simulation, the crystallographic directions were estimated from the symmetries of the facets [39]. The facets present correspond to $\{111\},\{110\},\{100\},\{113\}$ and $\{530\}$. It is worthy to note that $\{530\}$ facets are not typically reported for highly pure $\mathrm{Cu}$, but in this case, as explained by Meltzman et al. [40], the presence of carbon layers at the surface, modifies the anisotropy giving rise to the appearance of other facets.

\section{Conclusion}

We describe the formation of faceted core-shell $\mathrm{Cu}_{2} \mathrm{O}-\mathrm{rGO}$ and $\mathrm{Cu}-\mathrm{rGO}$ nanoparticles on the surface of a $\mathrm{Cu}$ foil by annealing foil-supported graphene oxide (GO) under an Ar atmosphere. The predominant phase as well as the particle size and shape strongly depend on the process temperature, in the ranges of
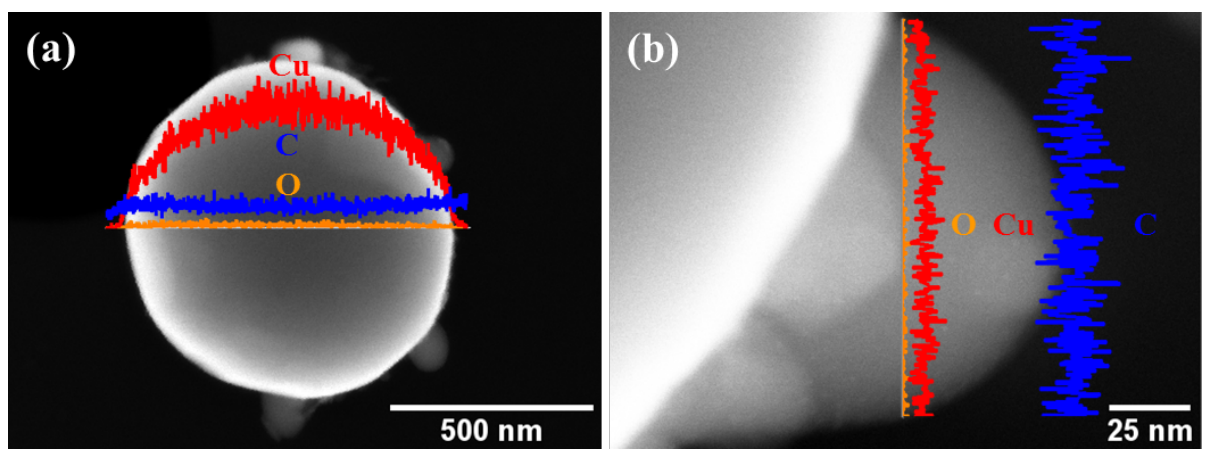

Figure 5: HAAF image and EDS line-scan profile across of (a) single particle showing carbon, copper and oxygen signals, (b) single nanorod showing the carbon, copper and oxygen signals. 


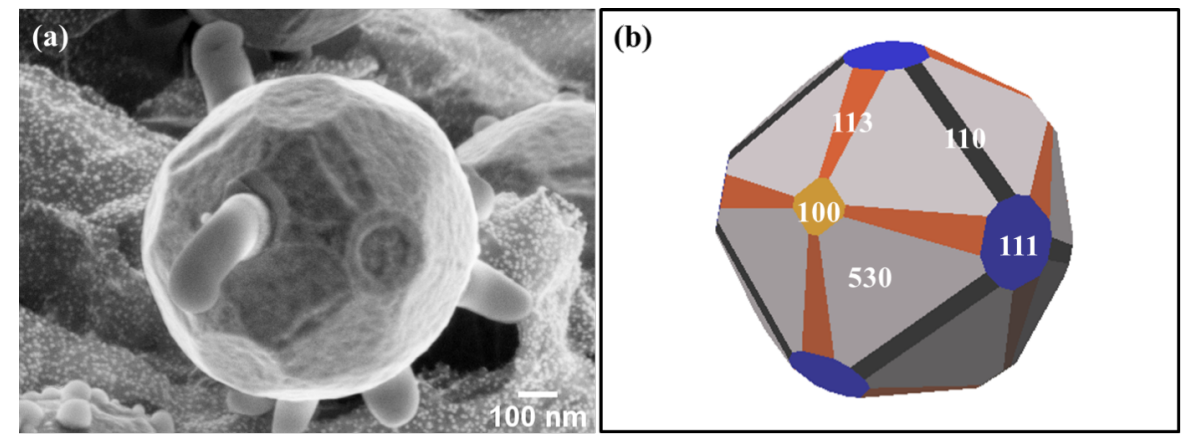

Figure 6: FE-SEM image of (a) single particle showing the different facets (b) schematic crystal shape created using the Wulffman freeware [37,38].

$200-600{ }^{\circ} \mathrm{C}$ and $800-1000{ }^{\circ} \mathrm{C}, \mathrm{Cu}_{2} \mathrm{O}$ or $\mathrm{Cu}$ were obtained, respectively. It was demonstrated that rGO plays a dual role of stabilizing and protecting the $\mathrm{Cu}$ nanoparticles from further oxidation. In particular, at $1000{ }^{\circ} \mathrm{C}$, the $\mathrm{Cu}$ nanoparticles exhibit an equilibrium crystal shape. The facets found out by simulation were $\{111\},\{110\},\{100\},\{311\}$ and $\{530\}$. The faceted nanoparticles display arm-like carbon nanorods originating from different facets of the copper crystal structure.

\section{Acknowledgements}

This project is supported by the National Council of Science and Technology (CONACyT) No. CB2009-128723, and scholarship No. 355201, also by the Institute of Science and Technology of Federal District (ICyT 326/11). The authors are very thankful to Dr. Jaime Santoyo Salazar for his valuable assistance for TEM characterization, also LANE-Cinvestav, especially Dr. Josué Romero Ibarra and Dr. Daniel Bahena Uribe for the FE-SEM and HR-TEM characterization.

\section{References}

1. Liu, S.; Wang, L.; Tian, J.; Lu, W.; Zhang, Y.; Wang, X.; Sun, X. J. Nanopart. Res. 2011, 13, 4731-4737. doi:10.1007/s11051-011-0440-x

2. Das, T. K.; Prusty, S. Polym.-Plast. Technol. Eng. 2013, 52, 319-331. doi:10.1080/03602559.2012.751410

3. Gao, N.; Fang, X. Chem. Rev. 2015, 115, 8294-8343. doi:10.1021/cr400607y

4. An, X.; Li, K.; Tang, J. ChemSusChem 2014, 7, 1086-1093. doi:10.1002/cssc.201301194

5. Xu, C.; Cui, A.; Xu, Y.; Fu, X. Carbon 2013, 62, 465-471. doi:10.1016/j.carbon.2013.06.035

6. Bai, H.; Li, C.; Shi, G. Adv. Mater. 2011, 23, 1089-1115. doi:10.1002/adma.201003753

7. Bai, S.; Shen, X. RSC Adv. 2012, 2, 64-98. doi:10.1039/C1RA00260K

8. Huang, X.; Qi, X.; Boey, F.; Zhang, H. Chem. Soc. Rev. 2012, 41, 666-686. doi:10.1039/C1CS15078B

9. Gawande, M. B.; Goswami, A.; Asefa, T.; Guo, H.; Biradar, A. V.; Peng, D.-L.; Zboril, R.; Varma, R. S. Chem. Soc. Rev. 2015, 44, 7540-7590. doi:10.1039/C5CS00343A
10. Sunny, V.; Sakthi Kumar, D.; Yoshida, Y.; Makarewicz, M.; Tabiś, W.; Anantharaman, M. R. Carbon 2010, 48, 1643-1651. doi:10.1016/j.carbon.2010.01.006

11. Park, J. B.; Jeong, S. H.; Jeong, M. S.; Kim, J. Y.; Cho, B. K. Carbon 2008, 46, 1369-1377. doi:10.1016/j.carbon.2008.05.011

12. Wang, S.; Huang, X.; He, Y.; Huang, H.; Wu, Y.; Hou, L.; Liu, X.; Yang, T.; Zou, J.; Huang, B. Carbon 2012, 50, 2119-2125. doi:10.1016/j.carbon.2011.12.063

13. Zhao, Y.; Zhang, Y.; Li, Y.; Yan, Z. New J. Chem. 2012, 36, 1161-1169. doi:10.1039/c2nj21026f

14. Zhai, J.; Tao, X.; Pu, Y.; Zeng, X.-F.; Chen, J.-F. Mater. Res. Bull. 2011, 46, 865-870. doi:10.1016/j.materresbull.2011.02.012

15. Luo, N.; Li, X.-J.; Liu, K.-X.; Ye, L.-M.; Chen, T.-W. J. Nanopart. Res. 2013, 15, 1614. doi:10.1007/s11051-013-1614-5

16. Li, H.; Kang, W.; Xi, B.; Yan, Y.; Bi, H.; Zhu, Y.; Qian, Y. Carbon 2010, 48, 464-469. doi:10.1016/j.carbon.2009.09.063

17. Jacob, D. S.; Genish, I.; Klein, L.; Gedanken, A. J. Phys. Chem. B 2006, 110, 17711-17714. doi:10.1021/jp063842e

18. Ortega-Amaya, R.; Matsumoto, Y.; Pérez-Guzmán, M. A.; Ortega-López, M. J. Nanopart. Res. 2015, 17, 397. doi:10.1007/s11051-015-3201-4

19. Hummers, W. S., Jr.; Offeman, R. E. J. Am. Chem. Soc. 1958, 80, 1339. doi:10.1021/ja01539a017

20. Chen, W.; Yan, L.; Bangal, P. R. Carbon 2010, 48, 1146-1152. doi:10.1016/j.carbon.2009.11.037

21. Glover, R. D.; Miller, J. M.; Hutchison, J. E. ACS Nano 2011, 5, 8950-8957. doi:10.1021/nn2031319

22. Olson, E. A.; Efremov, M. Yu.; Zhang, M.; Zhang, Z.; Allen, L. H. J. Appl. Phys. 2005, 97, 034304. doi:10.1063/1.1832741

23. Frenken, J. W. M.; van der Veen, J. F. Phys. Rev. Lett. 1985, 54, 134-137. doi:10.1103/PhysRevLett.54.134

24. Mei, Q. S.; Lu, K. Prog. Mater. Sci. 2007, 52, 1175-1262. doi:10.1016/j.pmatsci.2007.01.001

25. Buffat, P.; Borel, J. P. Phys. Rev. A 1976, 13, 2287-2298. doi:10.1103/PhysRevA.13.2287

26. Matula, R. A. J. Phys. Chem. Ref. Data 1979, 8, 1147-1298. doi:10.1063/1.555614

27. Yeshchenko, O. A.; Dmitruk, I. M.; Alexeenko, A. A.; Dmytruk, A. M. Phys. Rev. B 2007, 75, 085434. doi:10.1103/PhysRevB.75.085434

28. Acik, M.; Lee, G.; Mattevi, C.; Pirkle, A.; Wallace, R. M.; Chhowalla, M.; Cho, K.; Chabal, Y. J. Phys. Chem. C 2011, 115, 19761-19781. doi:10.1021/jp2052618 
29. Wang, X.; Hanson, J. C.; Frenkel, A. I.; Kim, J.-Y.; Rodriguez, J. A.

J. Phys. Chem. B 2004, 108, 13667-13673. doi:10.1021/jp040366o

30. Goldstein, E. A.; Mitchell, R. E. Proc. Combust. Inst. 2011, 33, 2803-2810. doi:10.1016/j.proci.2010.06.080

31. Svintsitskiy, D. A.; Kardash, T. Yu.; Stonkus, O. A.; Slavinskaya, E. M.; Stadnichenko, A. I.; Koscheev, S. V.; Chupakhin, A. P.; Boronin, A. I. J. Phys. Chem. C 2013, 117, 14588-14599. doi:10.1021/jp403339r

32. Williams, E. D.; Bartelt, N. C. Ultramicroscopy 1989, 31, 36-48. doi:10.1016/0304-3991(89)90032-6

33. Chatain, D.; Ghetta, V.; Wynblatt, P. Interface Sci. 2004, 12, 7-18. doi:10.1023/B:INTS.0000012290.07441.a8

34. Hong, J.-S.; Jo, W.; Ko, K.-J.; Hwang, N. M.; Kim, D.-Y. Philos. Mag. 2009, 89, 2989-2999. doi:10.1080/14786430903164598

35. Zhang, W.-B.; Chen, C.; Zhang, S.-Y. J. Phys. Chem. C 2013, 117, 21274-21280. doi:10.1021/jp404569m

36. Chatain, D.; Wynblatt, P.; Rohrer, G. S. Acta Mater. 2005, 53, 4057-4064. doi:10.1016/j.actamat.2005.05.009

37. Roosen, A. R.; McCormack, R. P.; Carter, W. C. Comput. Mater. Sci. 1998, 11, 16-26. doi:10.1016/S0927-0256(97)00167-5

38. García, R. E.; Blendell, J. nanoHUB.org - Resources: Equilibrium Wulff Shape Generator. 2014; https://nanohub.org/resources/wulffman (accessed Nov 21, 2015). doi:10.4231/D3C53F234

39. Curiotto, S.; Chien, H.; Meltzman, H.; Wynblatt, P.; Rohrer, G. S.; Kaplan, W. D.; Chatain, D. Acta Mater. 2011, 59, 5320-5331. doi:10.1016/j.actamat.2011.05.008

40. Meltzman, H.; Chatain, D.; Avizemer, D.; Besmann, T. M.; Kaplan, W. D. Acta Mater. 2011, 59, 3473-3483. doi:10.1016/j.actamat.2011.02.021

\section{License and Terms}

This is an Open Access article under the terms of the Creative Commons Attribution License (http://creativecommons.org/licenses/by/2.0), which permits unrestricted use, distribution, and reproduction in any medium, provided the original work is properly cited.

The license is subject to the Beilstein Journal of Nanotechnology terms and conditions:

(http://www.beilstein-journals.org/bjnano)

The definitive version of this article is the electronic one which can be found at: $\underline{\text { doi:10.3762/bjnano.7.93 }}$ 